\title{
Adequações do setor de Fisioterapia Aquática da AACD na pandemia de COVID-19
}

\author{
Adaptations of the AACD Aquatic Physiotherapy department \\ in the COVID-19 pandemic
}

\author{
Adaptaciones del sector de Fisioterapia Acuática AACD en la \\ pandemia COVID-19
}

\author{
Douglas Martins Braga1 ${ }^{1}$ Rafael Santos Ferreira da Silva², \\ Caio Roberto Aparecido de Paschoal Castro ${ }^{3}$
}

\begin{abstract}
1.Fisioterapeuta pela Universidade Cidade de São Paulo, Especialista em Neurologia e Neurociências, Mestre em Ciências da Saúde pela Universidade Federal de São Paulo, Supervisor em reabilitação do setor de Fisioterapia Aquática da Associação de Assistência à Criança Deficiente (AACD), São Paulo-SP, Brasil.

2.Fisioterapeuta pelo Centro Universitário Faculdades Metropolitanas Unidas, Fisioterapeuta do setor de Fisioterapia Aquática da AACD, São Paulo-SP, Brasil.

3.Fisioterapeuta pelo Centro Universitário Faculdade Sudoeste Paulista, Especialista em fisiologia dos exercícios pela Universidade Paulista, Mestrando em Ciências da Saúde pela Faculdade de Ciências Médicas da Santa Casa de São Paulo, Fisioterapeuta do setor de Fisioterapia Aquática da AACD, São Paulo-SP, Brasil.
\end{abstract}

\begin{abstract}
Resumo
Introdução. A pandemia causada pelo novo Coronavirus acometeu e levou ao óbito muitas pessoas no Brasil. Por conta da gravidade da crise, as empresas criaram programas de adequações. A AACD interrompeu seus atendimentos entre 23/03/2020 e 15/06/2020. O setor de fisioterapia aquática necessitou criar um protocolo de retorno às atividades com segurança, baseado em relatos científicos de outros países e associações. Os atendimentos na piscina voltaram a ser realizados dia 17/08/2020. Objetivo. Compartilhar as medidas de segurança adotadas para o retorno das atividades no setor de fisioterapia aquática da AACD durante a pandemia de COVID-19. Método. Foi desenvolvido um protocolo de retorno aos atendimentos na piscina, baseado nos órgãos mundiais de saúde e na legislação nacional, pensando em aspectos fundamentais como elegibilidade do paciente e adequação do ambiente. Resultados. Foram incluídos pacientes mais independentes na piscina, que aceitassem a utilização da máscara. A elegibilidade foi definida pela equipe de fisioterapeutas. Os parâmetros de cloro, $\mathrm{pH}$ e alcalinidade da água foram adequados para inativação e aferidos a cada duas horas. Foram modificados os horários das terapias para a higienização adequada dos materiais. Os terapeutas utilizaram as máscaras cirúrgicas e face shield e o distanciamento mínimo de $2 \mathrm{~m}^{2}$ para cada paciente e terapeuta. Regras de utilização de vestiários e armários foram definidas, além da continuidade da utilização do sistema de exaustão. Conclusão. O protocolo de retomada às atividades do setor de fisioterapia aquática foi realizado de forma segura e teve o intuito de servir como referência para outros serviços.
\end{abstract}

Unitermos. COVID-19; Reabilitação; Hidroterapia; Equipamentos de proteção

\begin{abstract}
Introduction. The pandemic caused by the new Coronavirus affected and led many people to death in Brazil. Due to the seriousness of the crisis, companies created adaptation programs. AACD interrupted its services between 03/23/2020 and 06/15/2020. The aquatic physiotherapy sector needed to create a protocol for returning to activities safely, based on scientific reports from other countries and associations. The attendance at the pool started again on $08 / 17 / 2020$. Objective. To share the safety measures adopted for the return of activities in the aquatic physiotherapy sector of AACD during the COVID-19 pandemic. Method. A protocol for returning to appointments at the pool was developed, based on global
\end{abstract}


health agencies and national legislation, thinking about fundamental aspects such as patient eligibility and adequacy of the environment. Results. The most independent patients were included in the pool, who accepted the use of the mask. Eligibility was defined by the team of physiotherapists. The chlorine, $\mathrm{pH}$ and water alkalinity parameters were adequate for inactivation and measured every two hours. The schedules of therapies have been modified for the proper cleaning of materials. The therapists used the surgical masks and face shield and the minimum distance of $2 \mathrm{~m}^{2}$ for each patient and therapist. Rules for the use of changing rooms and cupboards were defined, in addition to the continued use of the exhaust system. Conclusion. The protocol for resuming activities in the aquatic physiotherapy sector was carried out safely and was intended to serve as a reference for other services.

Keywords. COVID-19; Rehabilitation; Hydrotherapy; Protective equipment

\section{Resumen}

Introducción. La pandemia provocada por el nuevo coronavirus afectó y llevó a muchas personas a la muerte en Brasil. Debido a la gravedad de la crisis, las empresas crearon programas de adaptación. AACD interrumpió sus servicios entre el 23/03/2020 y el 15/06/2020. El sector de la fisioterapia acuática necesitaba crear un protocolo para volver a las actividades de forma segura, basado en informes científicos de otros países y asociaciones. La asistencia a la piscina se reanudó el 17/08/2020. Objetivo. Compartir las medidas de seguridad adoptadas para el retorno de actividades en el sector de fisioterapia acuática de la AACD durante la pandemia de COVID-19. Método. Se desarrolló un protocolo de retorno a citas en piscina, basado en agencias de salud global y legislación nacional, pensando en aspectos fundamentales como la elegibilidad del paciente y la idoneidad ambiental. Resultados. Se incluyeron en el grupo pacientes más independientes, que aceptaron el uso de la máscara. La elegibilidad fue definida por el equipo de fisioterapeutas. Los parámetros de cloro, $\mathrm{pH}$ y alcalinidad del agua fueron adecuados para la inactivación y se midieron cada dos horas. Se han modificado los horarios de terapias para la correcta limpieza de materiales. Los terapeutas utilizaron las mascarillas quirúrgicas y el protector facial y la distancia mínima de $2 \mathrm{~m}^{2}$ para cada paciente y terapeuta. Se definieron reglas para el uso de vestuarios y armarios, además del uso continuado del sistema de escape. Conclusión. El protocolo de reanudación de actividades en el sector de la fisioterapia acuática se llevó a cabo de forma segura y pretendía servir de referencia para otros servicios.

Palabras clave. COVID-19; Rehabilitación; Hidroterapia; Equipo de proteccion

Trabalho realizado na Associação de Assistência à Criança Deficiente (AACD), unidade Ibirapuera, na cidade de São Paulo-SP, Brasil

Endereço para correspondência: Caio RAP Castro. Av. Prof. Luiz Ignácio de Anhaia Mello 3.800, apto 91A. CEP 03294-100. São Paulo-SP, Brasil. E-mail: caio.paschoal11@hotmail.com

\section{INTRODUÇÃO}

A Associação de Assistência à Criança Deficiente (AACD) é uma instituição brasileira sem fins lucrativos, criada em 1950 e é referência na reabilitação física de crianças e adultos com desordens neurológicas. Ela é composta por 9 unidades, em 4 estados do Brasil. A AACD realiza atendimentos médicos e terapêuticos através de convênios de saúde, atendimentos particulares e 
atendimentos pelo Sistema Único de Saúde (SUS), contribuindo de forma expressiva com a sociedade ${ }^{1}$. A unidade central está localizada na cidade de São Paulo - SP e é composta pelo Hospital Abreu Sodré, Oficina Ortopédica e Centro de Reabilitação (CR $)^{1}$.

O setor de Fisioterapia Aquática (FA) da unidade central, localizado no $\mathrm{CR}$, é formado por uma equipe de 25 fisioterapeutas, além de profissionais e voluntários que auxiliam na higienização de equipamentos, transferências de pacientes e aferições dos parâmetros da qualidade da água das duas piscinas existentes. No setor de FA, são atendidos, em média, 680 pacientes por mês, totalizando aproximadamente 2.800 atendimentos mensais e cerca de 180 atendimentos diários.

As atividades realizadas dentro da piscina foram suspensas desde o dia 25/03/2020, por conta da pandemia causada pelo COVID-19.

O novo vírus é causado pelo SARS-CoV-2 e pode desencadear múltiplas infeç̧ões e acometimentos respiratórios, desde casos assintomáticos, até casos graves e ao óbito ${ }^{2-4}$. A transmissão do vírus ainda não está bem definida, porém existem relatos de transmissão através do ar, superfícies infectadas, alimentos e água contaminada e contato com as mãos ${ }^{5}$.

Dados atuais (03/08/2020) do Ministério da Saúde do Brasil $^{6}$ demonstram que 2.733 .896 pessoas já foram acometidas pelo vírus e 94.104 pessoas morreram. $\mathrm{Na}$ cidade de São Paulo já foram confirmados 230.375 casos e 
339.980 pessoas estão sendo monitoradas e aguardam resultados de exames $(02 / 08 / 2020)^{7}$. Além disso, 9.863 mortes já foram confirmadas na cidade de São Paulo e 5.777 óbitos ainda não tem resultados dos testes para a confirmação ou não de COVID-197.

Por conta do alto número de casos e óbitos na cidade, a Secretaria da Saúde do Município de São Paulo criou um plano para a retomada das atividades de forma gradativa em todas as áreas da sociedade ${ }^{7}$. Para atividades realizadas em piscinas, foi deliberada pela PORTARIA PREF 724, DE 10 DE JULHO DE $2020^{8}$, a diretriz de distanciamento interpessoal durante as atividades e a redução do tempo da atividade de cada indivíduo.

Para o retorno dos atendimentos de forma segura, o setor de FA desenvolveu um protocolo de prevenção baseado no Serviço de controle de infecção hospitalar da AACD e relatos científicos ${ }^{3-5}$ de outras associações e países: Associação Brasileira de fisioterapia aquática (ABFA) Brasili"; Asociación española de profesionales del sector piscinas (ASOFAP) - Espanha ${ }^{10}$; International aquatic therapy faculty (IATF) - Suiça ${ }^{11}$; International organisation of aquatic physical therapists (IOAPT) - Reino Unido ${ }^{12}$; Associazione italiana fisioterapisti (AIFI) - Itália ${ }^{13}$; Associação portuguesa de fisioterapeutas (APFisio) Portugal ${ }^{14}$.

O número de terapeutas (25) realizando atendimentos ao mesmo tempo no setor de FA da AACD central, é um caso atípico. Não encontramos referências de locais com esta 
quantidade de profissionais e com este volume de atendimento na piscina.

Portanto, o objetivo deste relato de experiência é compartilhar as medidas de segurança adotadas pelo setor de FA da AACD durante a pandemia, a fim de servir como uma referência para outros centros e profissionais desta área.

\section{Relato de retorno aos atendimentos}

A FA, é uma modalidade terapêutica que promove benefícios específicos aos pacientes e trabalha em conjunto com a fisioterapia convencional (em solo) para a reabilitação adequada do paciente com desordens neurológicas ${ }^{15}$.

Através dos princípios físicos e termodinâmicos da água e de outras variáveis, como, inclinação da piscina e nível de imersão, é possível que o paciente obtenha ganhos funcionais que possam ser transferidos para o solo ${ }^{15}$. Além disso, o ambiente aquático é lúdico, estimulador e desafiador, fato este que torna a terapia motivadora ${ }^{15,16}$. Por estes motivos, a FA é indispensável no programa de reabilitação de pacientes neurológicos ${ }^{15}$.

Em alguns países, como Estados Unidos, Itália e Espanha, foram desenvolvidos protocolos preventivos de higienização e de distanciamento interpessoal para o retorno de atividades esportivas e prática de exercícios dentro de piscinas $^{12-14}$. No Brasil, os estados e municípios planejaram o retorno destas atividades ${ }^{17}$. 
O protocolo de retorno das atividades no setor de FA da AACD central, baseou-se nos órgãos mundiais de saúde e na legislação nacional, levando em consideração dois aspectos fundamentais: Elegibilidade do paciente e Adequação do ambiente.

\section{Elegibilidade do Paciente}

Foram selecionados para o retorno dos atendimentos os pacientes adultos e adolescentes em período pós-operatório. Estes apresentavam maior independência na piscina e necessitavam de mínimo de contato corporal durante a terapia. As crianças com alto nível funcional e com bom comportamento para seguir as orientações, também foram elegíveis para o retorno.

Os pacientes que não se encaixaram nos critérios de elegibilidade foram atendidos em solo.

Após a seleção dos pacientes, a equipe assistencial realizou uma triagem de saúde, na qual foram feitos contatos telefônicos, em todos os dias anteriores às terapias de cada paciente. Esta triagem contemplou questionamentos referentes ao estado de saúde do paciente e familiares/cuidadores, através das seguintes perguntas e orientações:

- As pessoas que moram em sua casa estão bem de saúde? - Alguma pessoa que mora na sua casa teve algum sintoma de resfriado nas últimas duas semanas?

- Há alguém na sua casa com diagnóstico ou suspeita de Covid-19? 
- Se essas situações ocorrerem hoje ou até o dia da sua próxima terapia, por favor, não compareça e telefone para o setor, explicando o motivo da sua falta.

- Lembre-se de separar uma máscara devidamente limpa, para que você venha para a terapia na próxima semana, pois não é permitida a entrada na AACD sem ela, o paciente irá realizar a terapia na piscina somente com o uso de máscara própria.

Além da triagem telefônica, ao chegar na portaria da instituição, foi realizada a mensuração da temperatura corpórea do paciente e do acompanhante. Caso fosse observado estado febril, o paciente e o acompanhante eram orientados a procurar o pronto socorro mais próximo.

\section{Adequação do ambiente}

Segundo a Sociedade Brasileira de Infectologia ${ }^{18}$ o vírus não é transmissível através da água, assim como o Center of Diseases Control and Prevention (CDC) ${ }^{19}$, nos EUA, que citou não existirem evidências de que o vírus seja transmitido em piscinas, desde que esta seja higienizada adequadamente com cloro, o vírus é inativado. Outro estudo verificou que o hipoclorito de sódio, com concentração mínima de 0,21\%, apresenta uma eficácia de $99,8 \%$ na desinfecção ${ }^{5}$. O vírus causador da COVID-19, o SARS-CoV-2 é classificado como um vírus "envelopado", como os Cloxsackievirus, Poliovirus e Rotavirus, que são inativados pelo cloro 20-22.

A Organização Mundial da Saúde (OMS) ${ }^{23}$ afirma que uma concentração residual de cloro livre menor ou igual 
$0,5 \mathrm{ml} / \mathrm{L}$ na água da piscina, após pelo menos 30 minutos em contato à um $\mathrm{pH}$ menor que 8 é suficiente para inativar os vírus "envelopados", como o SARS-CoV-220-24. A operação de desinfecção adequada devem estar em conformidade com as normas locais, incluindo testes dos parâmetros físicoquímicos da água e testes bacteriológicos ${ }^{10-20}$.

A manutenção das piscinas da FA da AACD central é realizada a cada duas horas e compreende as atividades de limpeza (aspiração e limpeza de bordas), tratamento da água, visando manter os parâmetros adequados para as atividades terapêuticas: $\mathrm{pH}$ : de $7 \pm 0,4$, cloro entre 1 e $5 \mathrm{ppm}$ e alcalinidade entre 30 e 1209-11,21,22.

São realizadas, mensalmente, análises físico-químicas e microbiológicas da água da piscina, por um laboratório credenciado à AACD. Em caso de qualquer alteração, as atividades são interrompidas imediatamente até a adequação dos parâmetros da água.

O sistema de exaustão é fundamental para a prevenção do contágio, pois exerce a função de eliminar o excesso de umidade no ambiente da piscina, realizando a troca do ar, pois sabe-se que o vírus se propaga pelo ar por meio de gotículas suspensas ${ }^{5}$.

Todos os materiais da piscina e cadeiras de banho, utilizados para as transferências e para os atendimentos, são alocados em locais apropriados para higienização com peroxido de hidrogênio acelerado (AHP) e desinfetante hospitalar (bactericida, fungicida, virucida e tuberculicida) $)^{21,22-25}$. 
Outra adequação, foi o aumento do horário de terapia, de 35 minutos para 45 minutos. Isto reduziu o número de atendimentos diários ( 60 por dia) e o número de pessoas frequentando o setor de FA. Entre os atendimentos, foram reservados 15 minutos para a higienização do ambiente, vestiário e materiais. A jornada de trabalho dos fisioterapeutas foi reduzida para 15 horas semanais durante os meses de junho e julho de 2020.

Durante as terapias, o acompanhante ficava na sala de espera, do lado de fora da área das piscinas. Nesta área, o número de cadeiras foi diminuído e só foi permitida a entrada de um acompanhante por paciente. Os pertences dos pacientes, durante a terapia, deviam ficar com os seus respectivos acompanhantes.

O Artigo 16 - SP, LEI número 13.166, de 23 de janeiro de $1979^{26}$, relata que o número máximo de pessoas dentro de uma piscina ao mesmo tempo, não pode exceder à uma pessoa por metro quadrado. Porém, devido a pandemia, este número mudou para uma pessoa para cada 2 metros quadrados ${ }^{11-24,26}$. A IATF, através da nota técnica de 30 de abril de 2020, recomenda uma pessoa por metro quadrado no ambiente da piscina-11.

O aumento gradual de terapeutas e pacientes, acontecerá somente após novas diretrizes do plano da secretaria municipal de saúde. Estipulamos o distanciamento de 2 metros por dupla (paciente e terapeuta). Os atendimentos em grupo foram interrompidos. 
O uso de equipamento de proteção individual (EPI) durante 0 atendimento, se faz necessário ${ }^{27}$. Algumas discussões indicam que a utilização do protetor face shield, associado a máscara N95, ou a máscara cirúrgica, é mais eficiente $^{27}$ (Figura 1). Durante a análise da eficácia das máscaras, foi realizada a quantificação do vírus, capacidade de bloqueio do vírus em aerossóis, com os seguintes resultados: Máscaras N95 (99,98\%), máscara cirúrgica $(97,14 \%)$, máscara caseira ( 1 camada de tecido +4 folhas de papel toalha) $(95,15 \%)^{27}$.

Figura 1. Fisioterapeuta realizando o atendimento utilizando a máscara cirúrgica e face shield e paciente utilizando máscara (com autorização dos envolvidos).

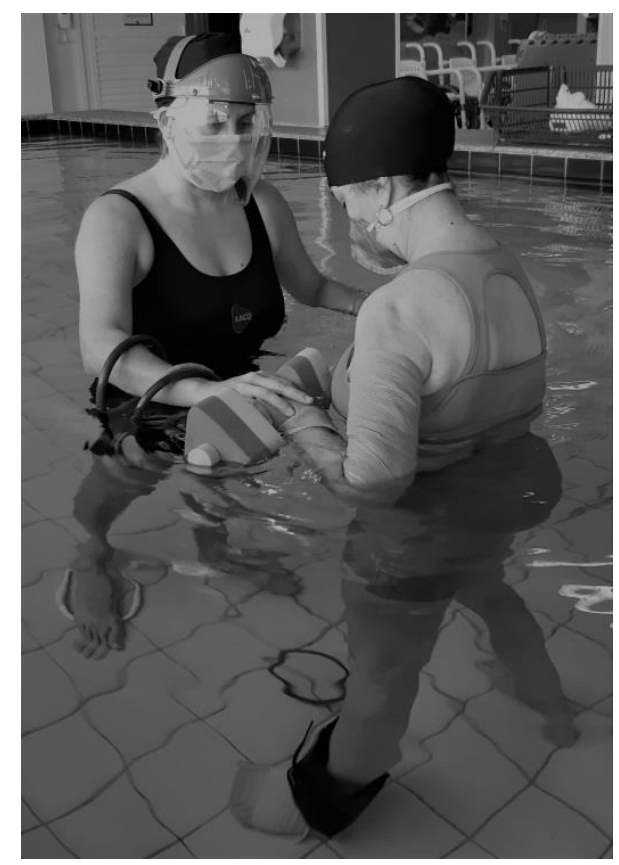

Os fisioterapeutas foram orientados à utilizar o protetor face shield associado à máscara cirúrgica. A troca das máscaras (paciente/fisioterapeutas) deviam ser realizadas em casos de umedecimento. 
Como medida preventiva, todos os fisioterapeutas realizaram treinamento de higienização das mãos, uso correto de máscaras e paramentação e desparamentação de EPI.

\section{Considerações finais}

Durante os meses de abril e maio de 2020, os pacientes atendidos no setor de FA da AACD tiveram seu tratamento interrompido devido a pandemia. Desta forma, o protocolo de retorno às terapias foi necessário para promover maior segurança durante às atividades. O consenso das diretrizes entre os órgãos de saúde e associações internacionais foi importante para o desenvolvimento deste protocolo. Portanto, o intuito deste relato é direcionar outros profissionais e centros de reabilitação para o retorno dos atendimentos na piscina de forma segura.

\section{REFERÊNCIAS}

1. Associação de assistência à criança deficiente (AACD). (acessado em agosto/2020). Disponível em: https://aacd.org.br/a-aacd

2.Tobaiqy M, Qashqary M, Al-Dahery S, Mujallad A, Hershan AA, Kamal MA, et al. Therapeutic management of patients with COVID-19: a systematic review. Inf Prev Pract 2020;2:100061. https://doi.org/10.1016/j.infpip.2020.100061

3. Liu Y, Gayle AA, Wilder-Smith A, Rocklöv J. The reproductive number of COVID-19 is higher compared to SARS coronavirus. J Travel Med 2020;27:1-4. https://doi.org/10.1093/jtm/taaa021

4.Zhai $\mathrm{P}$, Ding $\mathrm{Y}$, Wu $\mathrm{X}$, Long J, Zhong $\mathrm{Y}$, Li Y. The epidemiology, diagnosis and treatment of COVID-19. Int J Antimicrob Agents 2020;55:105955. https://doi.org/10.1016/j.ijantimicag.2020.105955 5. Eslami $\mathrm{H}$, Jalili M. The role of environmental factors to transmission of SARS-CoV-2 (COVID-19). AMB Express 2020;10:92. https://doi.org/10.1186/s13568-020-01028-0

6. Ministério da saúde do Brasil. Painel Coronavírus. (acessado em agosto/2020). Disponível em: https://covid.saude.gov.br/ 
7.Núcleo de comunicação do comitê de crise para enfrentamento ao COVID-19. Boletim diário COVID-19 da Prefeitura de São Paulo. (acessado em agosto/2020). Disponível em: https://www.prefeitura.sp.gov.br/cidade/secretarias/upload/saude/20 200802 boletim covid19 diario completo.pdf

8.PORTARIA PREFEITO - PREF NO 724 DE 10 DE JULHO DE 2020, (acessado em agosto/2020). Disponível em: http://legislacao.prefeitura.sp.gov.br/leis/portaria-prefeito-pref-724de-10-de-julho-de-2020/detalhe

9.COMUNICADO DA ABFA / Covid-19. Medidas COVID-19 (acessado em agosto/2020). Disponível em:

https://abfaquatica.com.br/comunicado-da-abfa

10.Associación española de profesionales del sector, ASOFAP P. Protocolo para las instalaciones acuáticas de uso público en un contexto de próxima apertura debido a la COVID-19. (acessado em agosto/2020). Disponível em: https://www.asofap.es/sites/default/files/documents/files/Protocolo Piscinas Saludables v3.pdf

11.Declaração IATF COVID-19 (acessado em agosto/2020). Disponível em: https://www.iatf.info/pdf/2020/COVID-

19 statement IATF Portuguese.pdf

12.Statement from the International Organization of Aquatic Physical Therapists (IOAPT) about COVID-19 and the practice of Aquatic Physiotherapy (acessado em agosto/2020). Disponível em: https://world.physio/sites/default/files/2020-06/IOAPT-Statement-

Covid-19-and-practice-of-Aquatic-Physiotherapy-12-05-20.pdf

13. Note sulla rimodulazione degli interventi di fisioterapia e riabilitazione in ambiente acquatico, nella fase dell'emergenza COVID19. Aggiornamento 25 Giugno 2020 (acessado em agosto/2020). Disponível em: https://aifi.net/wpcontent/uploads/2020/08/Aggiornamento-note-sulla-rimodulazionedegli-interventi-idrokinesiterapici-in-setting-DEF-2.pdf

14.Parecer do Grupo de Interesse em Fisioterapia Aquática (GIFA) da Associação Portuguesa de Fisioterapeutas (APFisio) (acessado em agosto/2020). Disponível em: http://gifa.apfisio.pt/index.php/documentos/folhetos-e-posters2/send/42-parecer-do-gifa/197-parecer-do-gifa-apfisio-sobre-apratica-de-fisioterapia-aquatica-hidroterapia-durante-a-fase-dedesconfinamento

15.Silva JB, Branco FR. Fisioterapia aquática funcional. São Paulo: Ed. Artes Médicas. 2011.

16. Bert F, Braga D. Qualidade de vida dos fisioterapeutas e colaboradores do setor de fisioterapia aquática da Associação de Assistência à Criança Deficiente (AACD). Rev Bras Qual Vida 2014;6:95-103. https://doi.org/10.3895/S2175-08582014000200004 17.COMUNICADO DA ABFA / Covid-19 - n.2 de 6 de maio de 2020. (acessado em agosto/2020). Disponível em: https://abfaquatica.com.br/comunicado-da-abfa-covid-19-n-2/ 
18. Informe da sociedade brasileira de infectologia (SBI) sobre o novo coronavírus $\mathrm{n}^{\circ} 10$ - perguntas e respostas para profissionais da saúde e para o público em geral (acessado em agosto/2020). Disponível em: https://web.infectologia.org.br/wp-

content/uploads/2020/07/informe-10-perguntas-gerais-covid-19.pdf 19. Centers for diseases control and prevention. COVID-19 - Frequently asked questions. (acessado em agosto/2020). Disponível em: https://www.cdc.gov/coronavirus/2019-ncov/php/water.html 20.Kampf G, Todt D, Pfaender S, Steinmann E. Persistence of coronaviruses on inanimate surfaces and their inactivation with biocidal agents. J Hosp Infect 2020;104:246-51. https://doi.org/10.1016/j.jhin.2020.01.022

21.Costa AO, Cruz EA, Galvão MSS, Massa NG. Esterilizaçäo e desinfecção: fundamentos básicos, processos e controles. São Paulo: Ed. Cortez., 1990, 77p.

22.Padoveze MC, Ku G. Limpeza, desinfecção e esterilização de artigos em serviços de saúde. São Paulo: APECIH, 2010, p.1-33.

23. World Health Organization. Water sanitation and health team. Guidelines for safe recreational water environments. Volume 2, Swimming pools and similar environments. Geneva: World Health Organization; 2006. (acessado em agosto/2020). Disponível em: https://apps.who.int/iris/handle/10665/43336

24.Astral pool. Pool \& Spa Guides. (acessado em agosto/2020). Disponível em: https://www.astralpool.com.au/are-pools-safe-duringcovid-19

25.Virox technologies Inc.T. Accelerated Hydrogen Peroxide $($ (AHP $囚)$ efficacy against SARS-CoV-2, the virus which causes COVID-19 disease. (acessado em agosto/2020). Disponível em: https://virox.com/common/source/CoronavirusProducts CDN 6.pdf

26. Norma técnica especial - NTE (1979). (acessado em agosto/2020). Disponível em: https://governosp.jusbrasil.com.br/legislacao/208164/decreto13166-79

27.Ma QX, Shan H, Zhang HL, Li GM, Yang RM, Chen JM. Potential utilities of mask-wearing and instant hand hygiene for fighting SARSCoV-2. J Med Virol 2020;92:1567-71. https://doi.org/10.1002/jmv.25805 